\title{
STUDY ON FACTORS AFFECTING MORTALITY IN PATIENTS WITH BRAIN TRAUMATIC INJURIES RESULTING FROM TRAFFIC ACCIDENT BY USING DATA MINING
}

\author{
Type of article: conference abstract \\ Leila Erfannia1, Ahmad Raeesi*2, Saeid Ebrahimi3 \\ 1: Ph.D Candidate in Health Information Management, Department of Health \\ Information Management, School of of Management and Medical Information Sciences, \\ Iran University of Medical Sciensces, Tehran, Iran \\ $2{ }^{*}$ : MSc Student in Medical Informatics, Department of Health Information Sciensces, \\ School of of Management and Medical Information Sciences, Kerman University of \\ Medical Sciensces, Kerman, Iran \\ 3: Faculty member of Health Information Technology, Department of Health Information \\ Technology, School of Paramedicine, Zahedan University of Medical Sciensces, Zahedan, \\ Iran \\ * Tel: +98.9159950428, E-mail: ah.raesse@gmail.com
}

\begin{abstract}
Introduction: One of the most important health problems is road traffic accident. Brain traumatic injury caused by crashes is the first cause of mortality among young people. Capabilities of Data Mining methods to find factor affecting and the prediction therapeutic outcomes leads to the improvement and effectiveness of the services. The aim of this study was to find the Factors affecting mortality in patients with brain traumatic injuries resulting from traffic accident by using the C5.0 decision tree and Bayesian network data mining methods.
\end{abstract}

Methods: In this cross-sectional study, the population of this study was 106 records of patients with brain traumatic injury caused by traffic accident referred in Khatam-al-Anbia hospital in Zahedan city. Data were collected with a researcher-made checklist that was prepared in consultation with experts in this field and review of previous studies. The validity of this checklist was confirmed by three health information technology experts. Data were analyzed with using two software SPSS MODELER 18.0 and SPSS Statistics 24.

Results: The accuracy of C5.0 decision tree and Bayesian network were $84.9 \%$ and $74.5 \%$ obtained. The most important variables that affect the death of accidental patients include Type of lesions, the work of the person in an accident (driver, passenger, pedestrian), accident location (inside or outside the city), and age of the patient. According to the result of this study, the type of lesions with the cause of death ( $p$-value $=0.024)$ is statistically significant.

Conclusion: The results of C5.0 decision tree and Bayesian network showed the most important and effective variable is type of lesions. Hence, by predicting the 
Medical Technologies Journal, Volume: 1, Issue: 4, October-December 2017, Pages:76-136. Doi :

https://doi.org/10.26415/2572-004X-vol1iss4

factors affecting in death of brain traumatic patients, healthcare provider with timely action can reduce the death and irreparable of injuries of these patiants.

KEYWORDS: Brain traumatic injuries, Traffic accident, Data Mining, C5.0 decision tree, Bayesian network

\section{Declaration of conflicts}

This abstract is selected from the First International Congress of Diseases and Health Outcomes Registry and First National Congress of Medical Informatics, 14-17 February 2017, Mashhad, Iran

\section{Authors' biography}

No biography.

\section{References}

No references. 